Introduction Exercise capacity in chronic obstructive pulmonary disease (COPD) is limited both by abnormal pulmonary mechanics, reported as breathlessness, and by leg muscle fatigue. To improve functional capacity it is important to understand the primary physiological constraint. Neural respiratory drive (NRD), measured using the diaphragm electromyogram expressed as a proportion of maximum $\left(\mathrm{EMG}_{\mathrm{di}} \%\right.$ max), quantifies the load on the respiratory muscles imposed by abnormal pulmonary mechanics, and relates closely to breathlessness. We hypothesised that end-exercise $\mathrm{EMG}_{\mathrm{di}} \%$ max would be higher in patients stopping because of breathlessness than in those stopping because of leg fatigue.

Methods $\mathrm{EMG}_{\mathrm{di}}$, ventilation $\left(\mathrm{V}_{\mathrm{E}}\right)$, oxygen consumption $\left(\mathrm{VO}_{2}\right)$ and ventilatory reserve $\left(\mathrm{V}_{\mathrm{E}} / \mathrm{MVV} \%\right)$ were measured in $23 \mathrm{COPD}$ patients (median (IQR) $\mathrm{FEV}_{1} 39$ (30.0 to 56.8)\%predicted) during exhaustive cycle ergometry. Differences in physiological variables between groups of patients stopping because of breathlessness, leg fatigue or both were examined using 1-way ANOVA.

Results $\mathrm{EMG}_{\mathrm{di}} \%$ max was higher in patients stopping because of breathlessness ( $\mathrm{n}=12, \mathrm{EMG}_{\mathrm{di}} \% \max 75.7$ (69.5 to 77.1)\%) than in those stopping because of leg fatigue $\left(\mathrm{n}=8, \mathrm{EMG}_{\mathrm{di}} \%\right.$ $\max 44.1$ (39.4 to 63.3$) \%, \mathrm{p}<0.05)$. There were no significant differences in end-exercise $\mathrm{V}_{\mathrm{E}}$ or $\mathrm{VO}_{2} . \mathrm{V}_{\mathrm{E}} / \mathrm{MVV} \%$ tended to higher levels in the breathless group.

Discussion These results suggest that patients limited by breathlessness due to ventilatory constraints can be identified as those reaching near-maximal levels of NRD during exercise. Measurement of $\mathrm{EMG}_{\mathrm{di}} \%$ max during exercise could prove useful in identifying patients whose functional performance would be best optimised by improving pulmonary mechanics rather than interventions to train peripheral muscle groups.

\section{S54 NEURAL RESPIRATORY DRIVE MEASURED USING PARASTERNAL INTERCOSTAL MUSCLE ELECTROMYOGRAPHY IN PATIENTS WITH INTERSTITIAL LUNG DISEASE}

A Kaaba, C Jolley, v MacBean, C Reilly, S Birring, J Moxham, G Rafferty. King's College London, London, UK

\subsection{6/thoraxinl-2014-206260.60}

Introduction Forced vital capacity (FVC) and gas transfer (TLCO) are often used to assess disease severity and monitor progression in patients with interstitial lung disease (ILD). Difficulty in performing the required manoeuvres, particularly in severe disease, and inherent measurement variability makes detection of clinically important changes difficult using these parameters. There is, therefore, a need for new biomarkers in this patient group. Neural respiratory drive (NRD) reflects the load on the respiratory system and the capacity of the respiratory muscles. Parasternal intercostal muscle electromyography (EMGpara) provides a non-invasive measure of NRD which relates to disease severity and breathlessness in obstructive lung diseases. Measurements of EMGpara in ILD could potentially quantify overall disease severity.

Aim The aim of the study was to investigate the relationships between EMGpara, lung function, breathlessness, functional status and quality of life (QoL) in ILD.

Method EMGpara was measured in 45 patients with a range of fibrotic lung diseases using surface electrodes placed in the second intercostal spaces bilaterally. Mean peak root mean square EMGpara per breath was calculated and expressed as a percentage of maximum EMGpara (EMGpara\%max). The neural respiratory drive index (NRDI) was derived by multiplying EMGpara\%max by the respiratory rate. Spirometry and lung gas transfer were performed and the composite physiologic index (CPI) calculated. Six minute walk test (6MWT) and 4 metre gait speed (4MGS) were used to determine functional status. Health-related quality of life was assessed with the King's Brief Interstitial Lung Disease (K-BILD) and the St George's Respiratory Questionnaires (SGRQ). The Baseline Dyspnea Index (BDI) was used to grade breathlessness.

Results NRDI correlated significantly with VC\%predicted $(\mathrm{r}=$ $0.36, p=0.018)$ and the CPI $(r=0.40, p=0.01)$ No significant correlations were found between EMGpara or NRDI and breathlessness, QoL or functional status.

Conclusion EMGpara is a feasible measure in ILD. EMGpara correlates with prognostic markers suggesting potential value as a biomarker integrating important pathophysiological changes in lung mechanics in fibrotic ILDs. The lack of association with QoL measures and BDI requires further investigation.

\begin{tabular}{|c|c|c|c|}
\hline Parameter & Median & Range & Correlation with NRDI $(r=)$ \\
\hline Age (years) & 65 & $35-85$ & - \\
\hline BMI & 27.5 & $20.6-40.7$ & - \\
\hline $\mathrm{FEV}_{1} \%$ predicted & 82.5 & $41-148$ & $-0.38^{*}$ \\
\hline FVC\%predicted & 83 & $43-137$ & $-0.36^{*}$ \\
\hline TLCO\%predicted & 48 & $21-78$ & -0.25 \\
\hline EMGpara\%max (\%) & 8.1 & $3.4-20.2$ & - \\
\hline NRDI a.u. & 148 & $61-514$ & - \\
\hline K-BILD & 65 & $21-100$ & -0.007 \\
\hline SGRQ & 37 & $2.3-80$ & -0.74 \\
\hline BDI & 6 & -11 & -0.004 \\
\hline CPI & 44 & $9.8-64$ & $0.40^{*}$ \\
\hline 6MWD (\%predicted) & 58 & $18-130$ & -0.15 \\
\hline 4MGS $(\mathrm{m} / \mathrm{s})$ & 0.88 & $0.46-1.95$ & -0.21 \\
\hline
\end{tabular}

\section{S55} NEURAL RESPIRATORY DRIVE USING PARASTERNAL
ELECTROMYOGRAPHY IN CLINICALLY STABLE CYSTIC
FIBROSIS PATIENTS: A PHYSIOLOGICAL MARKER OF
LUNG DISEASE SEVERITY AND EXERCISE CAPACITY

${ }^{1} \mathrm{~L}$ Smith, ${ }^{2} \mathrm{CC}$ Reilly, ${ }^{1} \mathrm{~V}$ MacBean, ${ }^{1} \mathrm{CJ}$ Jolley, ${ }^{2} \mathrm{C}$ Elston, ${ }^{1} \mathrm{~J}$ Moxham, ${ }^{1} \mathrm{GF}$ Rafferty. ${ }^{1} \mathrm{Kings}$ College London, London, UK; ${ }^{2}$ Kings College Hospital, London, UK

\subsection{6/thoraxjnl-2014-206260.61}

Introduction Measurement of neural respiratory drive, using parasternal intercostal muscle electromyography (EMGpara), has previously been shown to relate to pulmonary function impairment and exercise-induced breathlessness in advanced cystic fibrosis (CF). This measure reflects the load on the respiratory system and the capacity of the respiratory muscles and therefore may provide a composite measure of overall lung disease severity. In order to utilise EMGpara clinically in CF, its relationship to standard physiological outcome measures requires further investigation across a broad range of disease severities. Aim: To investigate the relationships between EMGpara and standard measures of pulmonary function and exercise performance in patients with CF.

Methods Thirty patients with clinically stable CF were recruited. EMGpara was recorded during five minutes of tidal breathing using electrodes positioned in the second intercostal space directly lateral to the sternum. Peak EMGpara per breath was averaged over the final minute of the recording and expressed as a percentage of EMGpara recorded during a maximal inspiratory manoeuvre (EMGpara\%max). Spirometry, lung volumes by body 
Abstract S55 Table 1 Patient characteristics, EMG para\%max, measures of pulmonary function and exercise performance in thirty patients with CF

\begin{tabular}{|c|c|c|}
\hline & Median & Range \\
\hline Age & 24 & 16 to 47 \\
\hline BMI & 20.6 & 18.0 to 29.4 \\
\hline EMGpara\% $\max$ & 7.8 & 2.0 to 34.5 \\
\hline $\mathrm{FEV}_{1}$ (\% pred.) & 63.3 & 16.0 to 101.3 \\
\hline RV/TLC (\%) & 40.6 & 21.5 to 74.0 \\
\hline $\mathrm{FRC}_{\text {plett }} / \mathrm{TLC}(\%)$ & 58.9 & 41.2 to 78.6 \\
\hline ISWT (M) & 630 & 280 to 880 \\
\hline $\mathrm{VO}_{2 \text { peak }}(\mathrm{ml} / \mathrm{min} / \mathrm{kg})$ & 24.9 & 17.1 to 39.9 \\
\hline
\end{tabular}

plethysmography and an incremental shuttle walking test (ISWT) with breath by breath metabolic data were also performed.

Results Patient characteristics, EMGpara\%max, measures of pulmonary function and exercise performance are shown in Table 1. EMGpara\%max was significantly associated with residual volume/total lung capacity ratio (RV/TLC, $\mathrm{r}=0.724, \mathrm{p}<0.001$ ), forced expiratory volume in 1 second $\left(\mathrm{FEV}_{1} \%\right.$ pred. $\left.\mathrm{r}=-0.648, \mathrm{p}<0.001\right)$ and functional residual capacity/total lung capacity ratio $\left(\mathrm{FRC}_{\text {pleth }} / \mathrm{TLC}, \mathrm{r}\right.$ $=0.625, \mathrm{p}<0.001)$. EMGpara\%max showed the strongest relationship with ISWT distance $(\mathrm{r}=-0.612, \mathrm{p}<0.001)$ and peak oxygen uptake $\left(\mathrm{VO}_{2 \text { peak, }} \mathrm{r}=-0.665, \mathrm{p}=0.001\right)$. Weaker relationships were observed between ISWT distance and pulmonary function $\left(\mathrm{FEV}_{1} \mathrm{r}=\right.$ $0.518 \mathrm{p}=0.006$, RV/TLC $\mathrm{r}=-0.451 \mathrm{p}=0.024, \mathrm{FRC}_{\text {pleth }} / \mathrm{TLC} \mathrm{r}=$ $-0.299 \mathrm{p} 0.147)$ and $\mathrm{VO}_{2 \text { peak }}\left(\mathrm{FEV}_{1} \mathrm{r}=0.521 \mathrm{p}=0.008, \mathrm{RV} / \mathrm{TLC}\right.$ $\mathrm{r}=-0.505 \mathrm{p}=0.014, \mathrm{FRC}_{\text {pleth }} / \mathrm{TLC} \mathrm{r}=-0.389 \mathrm{p}=0.066$ ).

Conclusion EMGpara correlates strongly with conventional pulmonary function measures in $\mathrm{CF}$ and has a closer relationship with exercise capacity than standard pulmonary function parameters. EMGpara\%max therefore represents a promising marker of CF lung disease severity.

\section{S56 DIFFERENCES IN FORCED OSCILLATION TECHNIQUE BETWEEN HEALTHY INDIVIDUALS, OBSTRUCTIVE SLEEP APNOEA AND OBESITY HYPOVENTILATION SYNDROME}

${ }^{1} S$ Mandal, ${ }^{1}$ A Vaughan-France, ${ }^{2} \mathrm{~T}$ Dhir, ${ }^{1} \mathrm{ES}$ Suh, ${ }^{3} \mathrm{P}$ Pompilio, ${ }^{3} \mathrm{R}$ Dellaca, ${ }^{1} \mathrm{~N}$ Hart. ${ }^{1}$ Lane Fox Respiratory Unit, Guy's and St Thomas' Hospital, London, UK; ${ }^{2}$ King's College London, London, UK; ${ }^{3}$ Department of Electronic Informatics and Bioengineering, Politecnico Di Milano, Milan, Italy

\subsection{6/thoraxjnl-2014-206260.62}

Introduction Forced oscillation technique has been used to demonstrate expiratory flow limitation (EFL, by measurement of $\mathrm{DX}_{\mathrm{rs}, 5 \mathrm{~Hz}}$ ) in chronic obstructive pulmonary disease, however, this technique has not been widely used in the obese population. Obese individuals breathe at lower lung volumes and are therefore likely to develop EFL. We have previously demonstrated EFL occurs in individuals with obesity hypoventilation syndrome (OHS) but wished to determine if this also occurred in those with obstructive sleep apnoea (OSA) and compare differences between these groups.

Method Subjects with established OSA, OHS and healthy volunteers were recruited from the Lane Fox Respiratory Unit and Sleep Disorders Centre, St Thomas' Hospital. Subjects underwent measurements of height, weight, spirometry and EFL (ResmonPro, ResTech, Milan, Italy).

Results Eleven healthy (HC), 8 OSA and 9 OHS subjects were recruited, age $23.6 \pm 4.2,31.4 \pm 8.0$ and $58.9 \pm 10.4$ years respectively. Body mass index (BMI): healthy subjects $17.9 \pm 2.9$; OSA group $41.4 \pm 8.0$; OHS group; $46.8 \pm 9.3 \mathrm{~kg} / \mathrm{m}^{2}$, there were significant differences in BMI between the HC and OSA and OHS groups $(\mathrm{p}<0.001)$ but no difference between OSA and OHS. Spirometry (FEV1, FVC): HC $3.54 \pm 1.15,4.35 \pm 1.47$, OSA $2.55 \pm$ $0.85,3.27 \pm 1.03$ OHS $2.04 \pm 0.74,2.58 \pm 0.85$. In both the OSA and OHS groups $\mathrm{DX}_{\mathrm{rs}}$ increased with recumbency, as did the percentage of flow limited breaths (Table 1). Each group significantly increased their inspiratory resistance with the supine position compared to the upright seated position. There was a significant difference in $\mathrm{DX}_{\mathrm{rs}}$ between $\mathrm{HC}$ and OHS only in upright, $45^{\circ}$ and supine positions $(p<0.05)$. There was also a difference in the percentage of EFL breaths between $\mathrm{HC}$ and $\mathrm{OHS}$ in the $45^{\circ}$ and supine positions and between OSA and OHS in the $45^{\circ}$ position $(\mathrm{p}<0.05)$. Conclusion Patients with obesity and sleep disordered breathing experience EFL, which was more evident in the OHS group compared to the OSA group. This may be a consequence of their higher BMI impacting their lung volumes to a greater extent. Furthermore, the impact of position was greater in the OHS group suggesting that EFL may be a contributing factor in the development of hypercapnic respiratory failure in these individuals.

\section{S57 AEROBIC TRAINING AND DETRAINING IN COPD AND HEALTHY CONTROLS}

B Popat ${ }^{1}$, L Latimer ${ }^{1}$, L Houchen-Wolloff', C Bolton ${ }^{2},{ }^{1} \mathrm{M}$ Steiner. ${ }^{1}$ NIHR Respiratory BRU, Glenfield Hospital, Leicester, UK; ${ }^{2}$ Nottingham Respiratory Research Unit, Nottingham, UK

10.1136/thoraxjnl-2014-206260.63

Introduction Deconditioning is a key cause of exercise intolerance in COPD patients. Exercise training provides an effective method of improving aerobic exercise performance in this group. There is poor understanding on the trajectory of changes

Abstract S56 Table 1 Differences in expiratory flow limitation, as demonstrated by $\Delta \mathrm{X}_{\mathrm{rS}}$ between healthy controls, OSA and OHS

\begin{tabular}{|c|c|c|c|c|c|c|c|c|c|}
\hline & \multicolumn{3}{|l|}{ Healthy controls } & \multicolumn{3}{|c|}{ Obstructive Sleep Apnoea } & \multicolumn{3}{|c|}{ Obesity Hypoventilation Syndrome } \\
\hline & Upright Seated & $45^{\circ}$ & Supine & Upright Seated & $45^{\circ}$ & Supine & Upright Seated & $45^{\circ}$ & Supine \\
\hline $\mathrm{DX}_{\mathrm{rs}, 5 \mathrm{~Hz}}\left(\mathrm{cmH}_{2}\right.$ O.s. $\left.\mathrm{L}^{-1}\right)$ & $-0.15 \pm 0.13$ & $0.04 \pm 0.21^{*}$ & $-0.03 \pm 0.20$ & $0.52 \pm 0.74$ & $1.18 \pm 1.51$ & $2.05 \pm 2.23$ & $2.33 \pm 2.96$ & $4.45 \pm 2.91$ & $5.18 \pm 2.65^{*}$ \\
\hline$\%$ of EFL breaths & $0 \pm 0$ & $0 \pm 0$ & $0 \pm 0$ & $0 \pm 0$ & $20 \pm 27$ & $38 \pm 3$ & $35 \pm 45$ & $68 \pm 4$ & $73 \pm 34^{*}$ \\
\hline \multicolumn{10}{|l|}{ Inspiratory Reactance } \\
\hline$X_{\text {insp, } 5 \mathrm{~Hz}}\left(\mathrm{cmH}_{2}\right.$ O.s. L $\left.\mathrm{L}^{-1}\right)$ & $-0.55 \pm 0.21$ & $-0.67 \pm 0.43$ & $-0.69 \pm 0.43$ & $-0.93 \pm 0.89$ & $-2.47 \pm 1.66$ & $-1.91 \pm 0.91^{*}$ & $-2.60 \pm 0.95$ & $-3.38 \pm 1.80$ & $-2.69 \pm 1.75$ \\
\hline \multicolumn{10}{|l|}{ Inspiratory Resistance } \\
\hline $\mathrm{R}_{\text {insp }, 5 \mathrm{~Hz}}\left(\mathrm{cmH}_{2}\right.$ O.s. $\left.\mathrm{L}^{-1}\right)$ & $2.71 \pm 0.55$ & $3.45 \pm 0.66$ & $3.96 \pm 0.99^{*}$ & $4.31 \pm 1.34$ & $6.20 \pm 1.35$ & $6.43 \pm 1.52^{*}$ & $5.61 \pm 1.86$ & $6.42 \pm 1.05$ & $7.46 \pm 1.11^{*}$ \\
\hline R5-19insp & $-0.23 \pm 0.18$ & $0.04 \pm 0.21$ & $0.19 \pm 0.31^{*}$ & $0.37 \pm 0.49$ & $1.29 \pm 0.96$ & $1.29 \pm 0.56^{*}$ & $1.91 \pm 0.89$ & $2.20 \pm 0.60$ & $2.21 \pm 0.81$ \\
\hline Ti/Ttot & $0.44 \pm 0.04$ & $0.45 \pm 0.05$ & $0.45 \pm 0.03$ & $0.43 \pm 0.04$ & $0.45 \pm 0.03$ & $0.45 \pm 0.04$ & $0.41 \pm 0.05$ & $0.41 \pm 0.07$ & $0.43 \pm 0.07$ \\
\hline VE (L/min) & $14.26 \pm 7.06$ & $13.5 \pm 5.19$ & $14.62 \pm 7.58$ & $15.17 \pm 5.67$ & $17.72 \pm 5.02$ & $15.83 \pm 4.75$ & $20.88 \pm 9.44$ & $13.71 \pm 3.32$ & $13.3 \pm 2.62$ \\
\hline RR (bpm) & $15.75 \pm 1.99$ & $17.9 \pm 2.93^{*}$ & $17.5 \pm 2.95^{*}$ & $20.61 \pm 7.48$ & $21.59 \pm 6.52$ & $21.7 \pm 5.46$ & $22.14 \pm 6.90$ & $20.84 \pm 3.79$ & 19.321 .71 \\
\hline
\end{tabular}

